\title{
Simulation enhanced interprofessional education with nurse practitioner and medical students for patients with bipolar disorder: Facilitators and barriers in teamwork
}

\author{
Debra A. Scrandis * Kristin Bussell \\ School of Nursing, University of Maryland Baltimore, Baltimore, Maryland, United States
}

Received: September 22, 2015

DOI: $10.5430 /$ jnep.v6n3p88
Accepted: November 15, 2015 Online Published: November 27, 2015

URL: http://dx.doi.org/10.5430/jnep.v6n3p88

\begin{abstract}
The purpose of this qualitative study was to identify the facilitators and barriers in the process of learning teamwork and communication skills using a pilot simulation enhanced interprofessional education (Sim-IPE) project based on a case study of an individual living with bipolar disorder. Five student teams each composed of one nurse practitioner student and one medical student participated in two standardized patient sessions that included briefs and debriefs with trained facilitators. Teams also participated in two online sessions for planning purposes. Two researchers analyzed the digital recorded briefs and debriefs using content analysis. The results identified six themes: acknowledging, mutual support, communication, flexibility, team planning, and patient centered goals. Acknowledging one's own strengths and weaknesses early in the team development enabled trust building resulting in more effective planning and a highly functioning team. This Sim-IPE project can serve as a model for teaching teamwork for other disciplines and clinicians in psychiatric care. It is recommended that integrating this type of longitudinal Sim-IPE sessions into curricula of all health professions education can improve successful learning of teamwork in psychiatric care.
\end{abstract}

Key Words: Interprofessional education, Psychiatry, Simulation, Nurse practitioner students, Medical students

\section{INTRODUCTION}

Interprofessional teamwork among nurse practitioners and physicians is critical for successful outcomes in individuals with bipolar disorder. Bipolar disorder is a severe mental illness contributing to deficits in cognitive and social functioning. These individuals are two times more likely than the general population for premature death from cardiovascular disease, diabetes mellitus, chronic obstructive pulmonary disease, influenza, pneumonia, unintentional injuries and suicide. ${ }^{[1]}$ Frequently, substance use disorders and gambling addictions co-exist with bipolar disorder diagnoses and increase the complexity of treatment for these individuals..$^{[2,3]}$ Collaboration among providers through teamwork and communication can improve the lives of individuals with bipolar disorder. Teams composed of nurses, psychiatrists, patients with bipolar disorder and their families demonstrated improved overall functioning, cognitive functioning, autonomy, leisure time and physical health quality of life in these patients after 1 year compared to inconsistent treatment teams $(n=135) .{ }^{[4]}$

\footnotetext{
${ }^{*}$ Correspondence: Debra A. Scrandis; Email: dscra001@ son.umaryland.edu; Address: School of Nursing, University of Maryland Baltimore, Baltimore, Maryland, United States.
} 
Nurse practitioners and physicians are both involved in treating patients with bipolar disorder through primary and/or psychiatric care. However, there are misunderstandings between these two professions in regards to role autonomy of nurse practitioners and general understandings of physicians' role in health care. ${ }^{[5]}$ These issues remain today and affect teamwork and communication between providers, ultimately impacting patient care. A relatively recent concept analysis on nurse practitioner-physician collaborative practice ${ }^{[6]}$ identified the following needs to be accomplished for collaborative communication and interaction between the two professions: each individual's readiness, understanding and acceptance of each other's roles, confidence in each other's abilities, respect, trust and environmental support. Bridges $^{[6]}$ found non-collaborative work environments results in providers, who are dissatisfied, demonstrate lack of respect for each other and have role confusion, negatively influencing patient care. Outpatient psychiatric providers tend to have long-term relationships with patients experiencing bipolar disorder and their families, as well as other chronic mental illness, which may differ from more acute healthcare settings. There may be more consistent team membership in psychiatry so trust between nurse practitioners and physicians in this specialty is particularly important to provide improved care for these high risk patients.

Interprofessional education (IPE) is defined as "when students from two or more professions learn about, from, and with each other to enable effective collaboration and improve health outcomes". ${ }^{[7]}$ IPE is a method used in health professions training to develop interaction skills between different professions. Two core competencies cited as key for patient centered care are teamwork and communication skills. ${ }^{[8]}$ Curricula designs for both nurse practitioner and medical students consist of socialization into their own professional identities, however engaging both types of students with each other in interactive learning can teach collaboration skills for clinical practice. ${ }^{[9]}$ Simulation enhanced interprofessional education (Sim-IPE) allows students to develop team collaboration skills in a safe learning environment while replicating the health care setting and has become a preferred method for IPE. ${ }^{[10,11]}$ Best practices for Sim-IPE include appropriate team based structured debriefing and feedback while promoting collaborative teamwork and effective communication. ${ }^{[10]}$ There are no studies on Sim-IPE in psychiatric-mental health to our knowledge.

Quantitative measures of attitudes towards teamwork after an IPE experience provide a snapshot of each profession's perceptions. Developing teamwork and communication skills require having same team members work together over time especially with individuals with severe mental illness such

Published by Sciedu Press as bipolar disorder. The purpose of the qualitative aspect was to identify the facilitators and barriers in the process of learning teamwork and communication skills through a Sim-IPE project.

\section{Methods}

This project piloted a four-session Sim-IPE experience with medical and nurse practitioner student teams $(n=5$ teams) in Spring, 2015. Each team participated in an online collaborative session with the primary investigator to introduce TeamSTEPPs ${ }^{[12]}$ four teamwork concepts (Leadership, Situational Awareness, Mutual Support, Communication) (See Table 1) and skills to be used in the Sim-IPE experience. Teams also had opportunities to introduce themselves and discuss their prior experiences with teams. Teams participated in two standardized patient (SP) interactions (actors portraying patient cases) to practice teamwork skills. In the first session, each team needed to complete a new patient assessment together on a case study of a woman with bipolar disorder and multiple co-morbidities (dyslipidemia, substance use, obesity). The second session included delivering health education based on the same SP needs (weight control, smoking cessation). Teams participated in briefing and debriefing sessions with trained facilitators using Debriefing with Good Judgment model. ${ }^{[13,14]}$ The briefing sessions focused on identifying team roles and dividing up tasks for the SP session, while the debriefing sessions included the processing of emotions related to their SP experience and team performance. The questions used by the facilitators related to the four TeamSTEPPs concepts. Between the two SP scenarios, each team conducted another online session to plan the health education session with minimal faculty facilitation.

Researchers collected quantitative measures of the TeamSTEPPS skills using the PACT-Novice instrument. ${ }^{[15]}$ These data will be published at a later date. The qualitative section of this pilot study examined the development of teamwork and communication through the entire Sim-IPE using digital audio recordings. Written feedback statements from the standardized patients (SPs-actors portraying the case) were also used in the analysis. The University's ethical Internal Review Board approved the study.

\subsection{Recruitment and sample}

First year medical students in an accelerated psychiatric program and first/second year nurse practitioner students in either the family or psychiatric programs were recruited to participate in the study. Emails and in class invitations about the purpose of the study were presented to each target group. Students interested in participating contacted the primary 
investigator via email. Five student teams, each composed of recruited for the study. one medical student and one nurse practitioner student, were

Table 1. TeamSTEPPS four teamwork concepts, definitions and skill examples used in the simulation

\begin{tabular}{|c|c|c|}
\hline Concept & Definition & Skill Example \\
\hline Leadership & $\begin{array}{l}\text { Ability to maximize the activities of team members by } \\
\text { ensuring that team actions are understood, changes in } \\
\text { information are shared and team members have the } \\
\text { necessary resources }\end{array}$ & $\begin{array}{l}\text { Brief } \\
\text { (Short session before start to share plan, discuss team } \\
\text { formation, assign roles) }\end{array}$ \\
\hline $\begin{array}{l}\text { Situational } \\
\text { Awareness }\end{array}$ & $\begin{array}{l}\text { Process of actively scanning and assessing situational } \\
\text { elements to gain information or understanding or to } \\
\text { maintain awareness to support team functioning }\end{array}$ & $\begin{array}{l}\text { Cross Monitoring } \\
\text { (Monitor actions of other team members, provide } \\
\text { safety net, ensure mistakes are caught quickly, } \\
\text { “watching each other’s back”) }\end{array}$ \\
\hline Mutual Support & $\begin{array}{l}\text { Ability to anticipate and support team members' needs } \\
\text { through accurate knowledge about their responsibilities } \\
\text { and workload }\end{array}$ & $\begin{array}{l}\text { Task Assistance } \\
\text { (Team members foster climate where it is expected } \\
\text { that assistance will be sought and offered) }\end{array}$ \\
\hline Communication & $\begin{array}{l}\text { Structured process by which information is clearly and } \\
\text { accurately exchanged among team members }\end{array}$ & $\begin{array}{l}\text { Check-Back } \\
\text { (Sender initiates message, receiver accepts message } \\
\text { \& provides feedback, sender double-checks to ensure } \\
\text { message was received) }\end{array}$ \\
\hline
\end{tabular}

Note. Adapted from TeamSTEPPS 2.0, Agency for HealthCare Research and Quality. http://www.teamstepps.ahrq.gov

\subsection{Data analysis}

All online collaboration, briefing and debriefing sessions were audio recorded. Each recording was transcribed verbatim. Analysis was conducted with the Miles, Huberman and Saldana ${ }^{[16]}$ method of content analysis using NVivo qualitative software (QSR International). Coding was done in two cycles. The first cycle involved reading the transcripts in their entirety before identifying key codes or ideas from each session. Once codes were developed for each team, they were compared with all the teams for similarities and differences. The second cycle included collapsing similar codes into themes of facilitators and barriers in developing teamwork skills. Two researchers coded the transcripts in- dependently and came to a consensus on the themes. The researchers documented all conceptual and analytical processes during the analysis.

\section{RESUlts}

During the data analysis process, the following six themes emerged: acknowledging, mutual support, communication, flexibility, team planning, and patient centered approach (see Table 2). Key elements in each area were identified as essential to facilitating the team building experience, particularly in context to assessment and education with a patient having a psychiatric illness. When team members did not exhibit these themes, there were barriers in the success of the team.

Table 2. Examples of facilitators and barriers for interprofessional teamwork

\begin{tabular}{|c|c|c|c|c|c|c|}
\hline Themes & Acknowledging & $\begin{array}{l}\text { Mutual } \\
\text { Support }\end{array}$ & Communication & Flexibility & Team Planning & $\begin{array}{l}\text { Patient Centered } \\
\text { Approach }\end{array}$ \\
\hline \multirow{4}{*}{ Facilitators } & & Approval & Reciprocity & \multirow{4}{*}{$\begin{array}{l}\text { Trust } \\
\text { Agreements }\end{array}$} & Equality & Rapport \\
\hline & Sharing & Respect & Word Sensitivity & & Relinquish Control & Equal Team \\
\hline & Be Vulnerable & Feedback & Non Verbal Cues & & Brainstorm & Member \\
\hline & & Help Other & Conversation Skills & & Clarify Roles & Empowerment \\
\hline Barriers & $\begin{array}{l}\text { Preconceptions } \\
\text { Guardedness }\end{array}$ & $\begin{array}{l}\text { Leave } \\
\text { Team } \\
\text { Stranded }\end{array}$ & $\begin{array}{l}\text { Monopolize } \\
\text { Interruptions }\end{array}$ & $\begin{array}{l}\text { Controlling } \\
\text { Rigid Plan }\end{array}$ & $\begin{array}{l}\text { No Consensus } \\
\text { Discussions }\end{array}$ & $\begin{array}{l}\text { Omit } \\
\text { Collaboration with } \\
\text { Patient }\end{array}$ \\
\hline
\end{tabular}

\subsection{Acknowledging}

Acknowledging was the central aspect for all other themes. During the first briefing session, which occurred before SP encounter one, team members focused on establishing a level of trust as the foundation for their working relationship. Initially there was some discretion in sharing information, 
although for each pair the medical students took the initiative to be more forthcoming. Past experiences affected individual's preconceived notions and seemed to be related to the degree of discretion displayed.

"I have done some paired interviews in the psych program and an issue came up. I assumed it was okay if I interjected (during the patient interview) but my partner did not and was upset with me afterwards." "That experience just came back to me"

This step of making oneself vulnerable was key in establishment of trust between the team members, which in turn enhanced the planning stage. When posed the question, "What do you bring to the table?" it was most helpful for teamwork when each team member was able to acknowledge their areas of strength and weakness in terms of knowledge base, experience, personal attributes/deficits and self-confidence. The degree of self-disclosure seemed to be based on the individual's level of self-awareness related to these factors. The teams who were successful at establishing trust during the initial session were more effective in engaging and establishing trust with the patient. The following patient feedback reflects this dynamic.

"The students asked if there was anything they could do to make this transition easier and asked if there was anything special my previous provider did that I would like to continue. I felt very supported and cared for that they offered this and acknowledged how difficult transitioning can be."

The level of acknowledging strengths/weaknesses, past experiences, feelings/thoughts initially and during planning sessions had a direct effect on the quality of communication, flexibility, and mutual support in the teamwork process. For example in the debriefing session, there was acknowledging of feelings from one team member that elicited support from the other team member.

Med student: "I missed about the siblings thing. I was just so focused on one trail...train of thought...that I forgot..."

NP student: "You were doing great. I mean it's easy to miss because we had gotten to another subject, so it's hard to then remember, well siblings."

\subsection{Mutual support}

Elements of reciprocal support included mutual admiration/approval, ability to come to agreements, as well as pro-

Published by Sciedu Press viding reassurance and ongoing positive feedback, with such support leading to mutual respect and bonding in the team relationship. A common phenomenon that emerged during the planning phase was the importance to establish agreement related to interruption/interjection during the interview with the patient. This seemed to be necessary to provide a level of trust in working as a team rather than solo and also provided a "safety net" for times when each may feel "stuck", allowing the other to jump in and take over. Every team member had experienced a previous negative team situation, which was the contributing factor to wanting to establish an agreement. The stronger teams had a balance of "holding their tongue" to allow their partner to handle the situation and recognizing non-verbal cues from their partner to jump in and help. During the debriefing sessions, statements of positive affirmation to the other further increased trust, thereby enhancing flexibility and a willingness to acknowledge emotions and challenges during the patient interview. Improved bonding also resulted in more intuitive communication among the pair.

"It was critical to get a sense of what our dynamic is like and how we might communicate with each other, even though it was not planned out specifically, but we just got a more intuitive sense of what the other's personality is like. We could just read each other."

\subsection{Communication}

Multiple factors contributed to effective communication between team members and fostered the team building process, which in turn affected interactions with the patient during the assessment, planning and implementation phases. An important aspect of communication was the ability of team members to be mindful and aware of the words they chose and their nonverbal behaviors. Being able to recognize nonverbal cues such as gestures, facial expressions and voice tone enhanced the communication process. A reciprocal back and forth exchange between the team members during the planning phase enhanced the actual assessment and implementation with the patient. A barrier to effective team building was when one team member tended to monopolize the discussion and dominate over the other team player in the planning phase. Starting off in conversational discussion with the patient to "get to know" the person and expressing genuine concern also enhanced rapport building and engaged the patient as part of the team. This approach set the foundation for establishing a patient centered relationship resulting in more spontaneous communication and participation of the patient as an equal part of the team.

"It felt more like a group conversation." 
"It was just a better flow...was a discussion rather than us telling her these things."

Seating position also seemed to enhance the communication process during the patient session. Those teams that created more of a circle with the patient had a "flow" and the patient reported feeling more included as part of the team. During the session an ability of team members to be alert to nonverbal cues from both their partner as well as the patient enhanced more effective communication and detailed discussion of patient concerns. Modeling clear effective communication between the team enabled the patient to communicate thoughts, feelings and information about themselves more openly.

\subsection{Flexibility}

During the assessment phase flexibility was an essential element for the team process to flow smoothly. Having a plan in place beforehand, yet willingness to "not stick" to the assessment guide, created a milieu in which the client could feel comfortable to interact with both team members as a unit and participate as part of the team group. Barriers to this process were rigidity in division of tasks, following the assessment guide strictly in order and unwillingness to give up control. A primary factor in setting the groundwork for flexibility was an established agreement that each could interject during the assessment with the patient. A mutual attitude of team members to "go with the flow" resulted in the best adaptability during the interview process and relatedness with the patient Flexibility also seemed to be connected to the extent of trust established during the introduction and planning stages. The teams that established trust early on were much more flexible during their sessions with the patient, appearing to feel comfortable sharing the platform and even appreciating when the other "jumped in" with a question or comment to the patient. Although planning a structure was seen as very important, having flexibility during the interview was also essential to patient comfort as was expressed by one student.

"I feel like as flexible as you can be helps to improve comfort for the patients."

The teams who were less flexible, sticking too close to the interview guide and a specific order, seemed to miss important cues from the patient and opportunities for further exploration of an issue.

Patient feedback reflected, "The students missed the opportunity for empathy a few times when I mentioned binge drinking, a dead beat father, etc. I would have felt more comforted if the students had empathized."

\subsection{Team planning}

There were several essential elements in the team process that facilitated formation of a positive working relationship. The sharing of past experiences and identifying common experiences was helpful in establishing equality in their disciplines (medical doctor vs nurse practitioner) and a better understanding of their educational background. Once a team perspective was developed brainstorming of ideas occurred and a reciprocal flow of communication was exchanged. This was crucial in facilitating a plan for the assessment and teaching sessions with the patient.

"We were on the same page before we even walked in the door."

In the debriefing all team players identified having time for planning together as a critical factor in team success. Deciding on a strategy for splitting up the assessment and teaching responsibilities in advance was helpful but they often "rehashed" plans after meeting with the patient. It was also apparent that rapport building continued through this phase of working as a team and those with more established trust were able to plan in more depth surrounding patient needs.

Another aspect of the team process was negotiating roles. An essential component of determining team roles was establishing a sense of equality between disciplines starting with educating each other about their training and discipline. This situation was evident when one medical student was not informed of the role of a psychiatric nurse practitioner The planning of each person's tasks and responsibilities was based on level of comfort, skill and expertise in a content area rather than on discipline or hierarchy. This approach yielded a stronger team, which appeared to the patient as more informed and cohesive. It was most effective when the planning and agreement of roles was done collaboratively rather than in a dominant manner with one person assigning the responsibilities for the team. In the final debriefing students realized and voiced the notion that collaborative learning is quite useful and effective in fostering team process readiness skill.

"If you are learning next to the person too, then it just makes it seem more natural when you are working next to the person as well."

\subsection{Patient centered approach}

Team cohesion resulted in an approach that was comprehensive and patient centered, with an emphasis on patient empowerment. An initial effort to establish rapport and help the patient to feel comfortable involved conversation with the patient and taking time to "get to know them". Engaging 
them as an equal team member, and maintaining their control by including their priorities and ideas, resulted in patients feeling more empowered and motivated. Teams that had established trust in the initial phase of team building seemed much more attuned to patient cues during the assessment session and better able to allow the patient to "take the lead" in discussing their priorities during the teaching sessions. This approach also seemed to increase patient motivation surrounding lifestyle choices such as nutrition and activity level.

The SPs reported the perceived level of team cohesion observed during the assessment and teaching sessions. Teams with less flexibility were actually more confusing to the SPs as to who was "in charge" and did not feel to be an equal part of the team. Frequent barriers to the patient centered approach reported by the teams were mostly with the assessment tool. Teams found using the assessment tool in order flow of the interview. Team members sometimes interrupted the other member to ask clarifying questions that portrayed a mixed presentation to the SPs. The SPs reported they did not know who to talk to since both students were asking questions.

\section{DISCUSSION}

This study helps to increase knowledge in regards to several important aspects of the team building process for nurse practitioners and doctors in training. Starting the process with discussions about what factors influenced their decisions to go into health care and past experiences helped them understand each other before working together with the patient. Examination of personality and communication styles helps to foster self- awareness and the influence on being a team player. Exploring team members' experiences and strengths was beneficial in the planning of patient assessment and care. These foundational factors help to create team cohesion, which fosters a patient centered approach that invites the patient to be an equal part of the team.

Acknowledging emotions, thoughts, strengths and weaknesses throughout the process of developing teamwork and communication was key in this simulated experience. Participants varied in the time it took for them to acknowledge themselves as part of a team. The idea of acknowledging is supported in the literature with reflective practice methods used in debriefing sessions for examining one's own professional practice and assumptions behind these actions. ${ }^{[13]}$ It is interesting some teams developed trust more quickly than others even though all briefing and debriefing sessions were led by trained facilitators who can provide the safe space needed for disclosure of emotions and cognitive processes of the simulation. A sense of psychological safety is very important for students' experiences with simulations and debriefings. $^{[17]}$

The nurse practitioner students already had established a health care provider identity through their previous experiences as registered nurses and the medical students understood that the nurse practitioner students had more psychiatric and/or clinical experience. As a result, it was interesting to watch the medical students be flexible and open to this realization. Conversely these nurse practitioner students had previous interactions over time with physicians, possibly leading to a preconceived feeling of trust or lack of trust in their team member. Unfortunately, there was minimal exploration of these preconceptions in this study.

Another study ${ }^{[18]}$ discussed a similar experience with family nurse practitioner (FNP) students and physical therapy and athletic training students where there were variations in each discipline's attitudes about teamwork, shared participation and leadership. FNP students found teamwork was better, but shared participation was not valued, while the other disciplines found teamwork was poor, but there was shared participation. However, this simulation was conducted at one time rather than longitudinally. We used students who had a psychiatric focus so they may be more committed to this simulation versus other NP or medical students. These students were able to portray real providers during the simulation and get online resources for weight loss and smoking cessation on their own time. This group of students was able to treat the standardized patient as a real patient so this simulation enhanced IPE may serve as a successful model for semantical and phenomenal reality. ${ }^{[19]}$

An important question to further examine is the impact of structure on the team building process. In this study structure was provided at the onset from experienced facilitators and specific briefing/debriefing session goals. It is possible the opportunity and time for team players to figure out a structure together enhance the team building process and helped to reduce barriers. A pre-determined structure may help to establish boundaries and direction in the team building process. Interprofessional learning among psychiatric care providers is an ideal group since constructive team dynamics are essential in working with patients having mental illness, especially in that a treatment team approach is common in psychiatric care.

\section{Recommendations}

This Sim-IPE multiple session model demonstrates student teams need time to plan care before its delivery and for successful implementation. The key to developing teamwork with students is to establish trust and use briefs and debriefs 
over time to allow learning. This Sim-IPE could be used by other disciplines in psychiatry, such as social workers and psychologists and applied to mental health care in general. Since nurse practitioners are moving towards more autonomy with similar focuses on diagnoses and treatments, it is even more critical to learn communication and teamwork with physicians and others. It would be important to include the examination of the nurse practitioner and medical students' preconceptions about each other's profession before using this Sim-IPE. By being explicit about any preconceptions, student teams can work through any misconceptions, establish mutual respect and create a safe environment for working collaboratively. Implementing this Sim-IPE experience with clinicians and students before their clinical placements can be advantageous for practicing them in real situations.

\section{CONCLUSION}

This psychiatric Sim-IPE experience demonstrated key findings about facilitators and barriers for developing teamwork and communication skills in health profession students. By working with the same team members over time, trust and team building can enhance learning these skills for students' future clinical practice. Longitudinal Sim-IPE models may be the most advantageous for learning team based care. Faculty members can consider using these methods as requirements for health profession curricula to ultimately change outcomes for individuals with severe mental illness.

\section{CONFLiCTS OF INTEREST Disclosure}

The authors declare that there is no conflict of interest.

\section{REFERENCES}

[1] Crump C, Sundquist K, Winkleby MA, et al. Comorbidities and mortality in bipolar disorder: A Swedish national cohort study. JAMA Psychiatry. 2013; 70(9): 931-939. http://dx.doi.org/10.1001 /jamapsychiatry.2013.1394

[2] Carra G, Bartoli F, Cracamo C, et al. Attempted suicide in people with co-occurring bipolar and substance use disorders: Systematic review and meta-analysis. Journal of Affective Disorders. 2014; 167: 125-135. PMid:24955564 http://dx.doi.org/10.1016/j.jad .2014 .05 .066

[3] Di Nicola M, Tedeschi D, Mazza M, et al. Behavioural addictions in bipolar disorder patients: Role of impulsivity and personality dimensions Journal of Affective Disorders. 2010; 125: 8288. PMid:20083309 http://dx.doi.org/10.1016/j.jad. 200 9.12 .016

[4] van der Voort TYG, van Meijel B, Hoogendoorn AW, et al. Collaborative care for patients with bipolar disorder: Effects on functioning and quality of life. Journal of Affective Disorder. 2015; 179: 14-22. http://dx.doi.org/10.1016/j.jad.2015.03.005

[5] Martin DR, O'Brien JL, Heyworth JA, et al. The collaborative healthcare team: Tensive issues warranting ongoing consideration. Journal of the American Academy of Nurse Practitioners. 2005; 17(8): 325330. PMid:16045593 http://dx.doi/org/10.1111/j.1745-7 $599.2005 .0054 . x$

[6] Bridges S. Exploration of the concept of collaboration within the context of nurse practitioner-physician collaborative practice. Journal of the American Association of Nurse Practitioners. 2014; 26: 402-410. http://dx.doi.org/10.1111/1745-7599.12043

[7] World Health Organization. Framework for action on interprofessional education \& collaborative practice. Geneva: World Health Organization. 2010. Available from: http://www. who.int/hrh/ resources/framework_action/en/

[8] Interprofessional Education Collaborative. Core competencies for interprofessional collaborative practice: Report of an expert panel Washington DC: Interprofessional Education Collaborative. 2011. Available from: http://www. aacn.nche.edu/education-res ources/ipecreport.pdf

[9] Farrell K, Payne C, Heye M. Integrating interprofessional collaboration skills into the advanced practice registered nurse socializa- tion process. Journal of Professional Nursing. 2015; 31(1): 5-10. http://dx.doi.org/10.1016/j.profnurs.2014.05.006

[10] Decker SI, Anderson M, Boese T, et al. Standards of best practice: Simulation standard VIII: Simulation enhanced IPE (SimIPE). Clinical Simulation in Nursing. 2015; 11(6): 293-297. http: //dx.doi.org/10.1016/j.ecns.2015.03.010

[11] Palaganas JC, Epps C, Raemer DB. A history of simulation-enhanced interprofessional education. Journal of Interprofessional Care. 2014; 28(2): 110-115. http://dx.doi.org/10.3109/13561820.20 13.869198

[12] Agency for Healthcare Research and Quality. TeamSTEPPS 2.0. Available from: http://teamstepps.ahrq.gov/

[13] Rudolph JW, Simon R, Rivard P, et al. Debriefing with good judgment: Combining rigorous feedback with genuine inquiry. Anesthesiology Clinics. 2007; 25: 361-376. http://dx.doi.org/10.1016 /j.anclin.2007.03.007

[14] Salas E, Klein C, King H, et al. Debriefing medical teams: 12 evidence-based best practices and tips. The Joint Commission Journal on Quality and Patient Safety. 2008; 34(9): 518-527. PMid:18792656

[15] Chiu CJ, Brock D, Abu-Rish E, et al. Performance Assessment for Communication and Teamwork (PACT). University of Washington Center for Health Sciences Interprofessional Education, Research and Practice. 2011. Available from: http://collaborate.uw.edu/educators-toolkit/tools -for-evaluation/performance-assessment-of-communi cation-and-teamwork-pact-too

[16] Miles MB, Huberman AM, Saldana J. Qualitative data analysis: A methods sourcebook (3rd ed). Thousand Oaks, CA: Sage; 2014.

[17] Fey MK, Scrandis D, Daniels A, et al. Learning through debriefing: Students' perspectives. Clinical Simulation in Nursing. 2014; 10(5): e249-e256. http://dx.doi .org/10.1016/j . ecns . 2013 .12 .009

[18] Garrido M, Dlugasch L, Graber PM. Integration of interprofessional education and culture into advanced practice simulations. Clinical Simulation in Nursing. 2014; 10: 461-469. http://dx.doi.org/1 $0.1016 / j . e c n s .2014 .06 .001$

[19] Dieckmann P, Gaba D, Rall M. Deepening the theoretical foundations of patient simulation as social practice. Simulation in Healthcare. 2007; 2: 183-193. http://dx.doi.org/10.1097/SIH. 0b013e3 $180 \mathrm{f} 637 \mathrm{f} 5$ 